\title{
(国) QUEEN'S UNIVERSITY BELFAST

\section{The effects of interventions with physical activity components on adolescent mental health: Systematic Review and Meta-Analysis}

Neill, R., Lloyd, K., Best, P., \& Tully, M. A. (2020). The effects of interventions with physical activity components on adolescent mental health: Systematic Review and Meta-Analysis. Mental Health and Physical Activity, [100359].

\section{Published in:}

Mental Health and Physical Activity

\section{Document Version:}

Peer reviewed version

\section{Queen's University Belfast - Research Portal:}

Link to publication record in Queen's University Belfast Research Portal

\section{Publisher rights}

(C) 2020 Elsevier Ltd.

This manuscript is distributed under a Creative Commons Attribution-NonCommercial-NoDerivs License

(https://creativecommons.org/licenses/by-nc-nd/4.0/), which permits distribution and reproduction for non-commercial purposes, provided the author and source are cited.

\section{General rights}

Copyright for the publications made accessible via the Queen's University Belfast Research Portal is retained by the author(s) and / or other copyright owners and it is a condition of accessing these publications that users recognise and abide by the legal requirements associated with these rights.

Take down policy

The Research Portal is Queen's institutional repository that provides access to Queen's research output. Every effort has been made to ensure that content in the Research Portal does not infringe any person's rights, or applicable UK laws. If you discover content in the Research Portal that you believe breaches copyright or violates any law, please contact openaccess@qub.ac.uk. 
The effects of interventions with physical activity components on adolescent mental health: Systematic Review and Meta-Analysis

\section{Introduction}

Mental health is often defined as a state of well-being which can help an individual cope with their feelings and daily stressors (World Health Organisation, 2018; Mental Health Foundation, 2013). Currently, the prevalence of mental health problems has reached unprecedented levels globally (World Health Organisation, 2018; Rehm \& Shield, 2019; Schofield et al. 2019; Vigo et al. 2019). Anxiety, depression, and stress have been identified as common mental health issues impacting individuals worldwide (Rehm \& Shield, 2019; Mental Health Foundation, 2016; National Collaborating Centre for Mental Health, 2011). The increasing prevalence of these issues has a significant impact on physical health, social policy, human rights and economics (Schofield et al. 2019; Sickel, Seacat and Nabors, 2019; World Health Organisation, 2019). These issues account for 10-14\% of the global burden of disease (Schofield et al. 2019; World Health Organisation 2018) with further evidence indicating that mental health issues account for 183.9 million disability adjusted life years (Schofield et al. 2019; Whiteford et al. 2010).

This burden and increasing prevalence places a major burden on health resources. Mental health costs are surpassing all other health conditions with direct and indirect costs of \$1 billion a year from depression and anxiety (Vigo et al. 2019; Doran \& Kinchin, 2019; Evans, 2019; Pincherio, Ivandic and Razzouk, 2017; Trautmann \& Wittchen, 2016). Therefore, many governments have identified mental health as a priority area, particularly in young people (Mental Health Foundation, 2018; Silverstone at al. 2016; Keyes, 2013; Burnett-Zeigler et al. 2012). Young people have been categorized as an at-risk group for developing severe mental health disorders with one in five children and young people reporting poor mental health 

et al. 2013). Research suggests that during adolescence around 20 per cent of young people will suffer from anxiety, depression or stress related problems before the age of 18 (World Health Organization, 2018; Werner-Seidler et al. 2017). Due to this increasing prevalence of these mental health problems, research has suggested that early intervention during this transitional life phase is imperative to help promote positive mental health, and resilience in these adolescents (He et al. 2018; Weeks et al. 2017; Royal College of Psychiatrists, 2016; Fazel et al. 2014; Burnett-Zeigler et al. 2012; Moses, 2010; Olsson et al. 2003). Recent evidence suggests that these interventions could contain an element of physical activity to improve psychological outcomes such as anxiety and depression, in addition to addressing global youth inactivity levels (Jewett et al. 2014; Eime et al. 2013; Vina et al. 2012; Rangul et al. 2012; Ströhle, 2009; Salmon, 2001). In comparison to the unsustainable long-term costs of pharmacological (medication) or psychosocial approaches (psychotherapy or cognitive behaviour therapy, physical activity is considered as more feasible and cost-effective alternative as an intervention component (Gråstén, 2017; Weeks et al. 2017; Lam, 2016). This is particularly important as the World Health Organization have highlighted that four in five adolescents aged 11 to 17 years old are not meeting the recommended physical activity guidelines (who.int, 2019).

The relationship between physical activity and mental health, particularly anxiety and depression, has garnered a large amount of attention. Compelling evidence from a systematic review on physical activity as a treatment for severe mental health illness by the European Psychiatric Association (Stubbs et al. 2018) clearly illustrated the importance of physical activity and exercise as an alternative mental health treatment pathway to the traditional pharmacological and psychosocial approaches. The European Psychiatric Association have recommended that physical activity could be used to reduce mental health symptoms while 
improving quality of life, physical health and cognition in individuals who face mental health difficulties. Furthermore, three reviews conducted in the adolescent provided reliable evidence that physical activity can have a positive effect on mental health, particularly being used to reduce symptoms of anxiety and depression population, although the authors highlighted that further research is warranted due to the weak research design and small effects of the included reviews (Biddle et al. 2019; Camero et al. 2012; Biddle and Asare, 2011).

Extant research has demonstrated that it may be possible to positively influence mental wellbeing in young people through physical activity, which if sufficient enough can have a positive impact on anxiety, depression and stress disorders. For example, Bonhauser et al. (2005) examined the effects of improving physical fitness on the emotional well-being of 198 adolescents through a school-based intervention. The intervention programme involved three physical activity sessions weekly, each lasting 90 minutes. Over the academic year, the 40week programme involved different stretching, weight and sports activities for the intervention group, while the control group only received a standard 90-minute exercise class a week. The results of the study showed that anxiety and depression scores decreased, while self-esteem scores increased as a result of the intervention, thus suggesting that physical activity can have an effect on reducing the symptoms of these mental health outcomes. Furthermore, a study by He et al. (2018) reported that adolescents who were more physical active, were significantly less likely to suffer mental health issues.

Traditionally physical activity interventions look at increasing physical activity levels or improving physical fitness rather than a sole focus on mental health outcomes (Dobbins et al. 2012; Bonhauser et al. 2005) or focusing on other health outcomes such as obesity. The examination of mental health outcomes is currently understudied within the adolescent population. However, several intervention studies have examined psychosocial benefits such as academic achievement, cognitive functioning (Archer \& Garcia, 2014; Ardoy et al. 2014) 
and self-concept (Lubans et al. 2012; Lai et al. 2009). While these studies have highlighted an association between mental health and physical activity, little evidence is known about the causal relationship between physical activity on mental health outcomes in young people. The reason behind this is the complexity of measuring mental health and physical activity in the adolescent population, which may be why the majority of research in this area examines the relationship amongst the adult population (Kuhn et al. 2017; Mental Health Foundation, 2016; Fox, 1999). Promoting physical activity could be an important preventative strategy for mental health outcomes amongst adolescents, but more research is needed to determine this. To address the current evidence gaps, this systematic review will examine the effect of interventions with physical activity components on anxiety, depression and stress outcomes in young people. The objectives of the review were to:

- identify evidence on the effect of physical activity interventions on mental health outcomes; anxiety, stress and depression and

- identify the gaps in research evidence in order to make recommendations for future research.

\section{Methods}

This systematic review and meta-analysis complies with the Preferred Reporting Items for Systematic Reviews and Meta-analysis (PRISMA) guidelines (S1 File).

\subsection{Eligibility criteria}

A study was considered eligible for this review if it met the following inclusion criteria: (a) included participants aged between 10-19 years ; (b) examined interventions with physical activity components and measured anxiety, depression and stress outcomes; (c) included an intervention lasting longer than four weeks that contained physical activity alone, or as part of 
a multi-component intervention; and (d) investigated the effects of the intervention on anxiety, depression and stress. For studies to be included in the review they had to be a randomised or cluster randomised controlled trial (RCT).

Excluded studies were those which: (a) included participants from outside the included age bracket; (b) were published in languages other than English; (c) were conference abstracts, study protocols or dissertations; (d) were studies developing interventions without participants; (e) were studies without a relevant control group (i.e. control groups with exercise or physical activity as a component) and (f) were studies that only examined physical health outcomes or physical well-being.

\subsection{Search Strategy}

Electronic databases were searched in November 2019 with no restriction set on the publication year. Furthermore, the search strategy was limited to articles published in English language only. A systematic search was carried out across nine electronic databases including: British Education Index, Child Development and Adolescent Studies, CINAHL, Cochrane Central Register of Controlled Trials (CENTRAL), Embase, ERIC, Medline, Psychinfo and SportsDiscus. Search terms included a combination of common variants of young people and mental health outcomes. MEDLINE was used to develop the search strategy, which was then adapted for the other databases as necessary. The specific search terms are detailed in S2 File. To identify any further published or unpublished government reports and other grey literature, open grey (http://www.opengrey.eu/) was complemented with a web search on Google Scholar (https://scholar.google.co.uk/), using the phrase 'physical activity interventions and mental health in young people or adolescents', with the first 200 citations examined. In addition, manual searches for relevant publications in the following journals were carried out for the last three years (2016-2019); International Journal of Behavioural Nutrition 
and Physical Activity, Journal of Physical Activity and Health, Journal of Youth and

127 Adolescence, Journal of Adolescent Health, Journal of Child and Adolescent Mental Health, Journal of Psychology of Sport and Exercise, Journal of Sport and Exercise Psychology, Journal of Sport and Health Science, Journal of Medicine and Science in Sport and Exercise and the Journal of Mental Health and Physical Activity. Finally, the reference lists of all included studies were reviewed for relevant citations.

\subsection{Data Collection}

\subsubsection{Study Selection}

The initial literature searches were conducted by one reviewer (RN). After duplicates were removed using Covidence (Vertias Health Innovation, 2015) title and abstracts of potentially relevant articles were independently screened by RN and MT. After this initial phase, the relevant full text of the remaining articles were independently screened and evaluated for inclusion by RN and MT according to the inclusion criteria. Any discrepancies were resolved through discussion between the two reviewers to determine the eligibility of the study for the review (RN and MT). Consensus was obtained for all relevant included journal articles.

\subsubsection{Data extraction}

Two reviewers (RN and MT) independently extracted characteristics, population, intervention, outcomes and analysis from each study. In the case of disagreements, a third reviewer (PB) was consulted. Information from each study was extracted onto Covidence (Vertias Health Innovation, 2015) and then exported to Review Manager 5.3. (RevMan - Cochrane Collaboration, 2014). Information extracted included; type of study, number of participants, outcome measures, details on intervention (setting, duration, frequency, duration, 
providers/resources, theoretical framework, content, control), study length, significant findings and risk of bias.

\subsubsection{Risk of bias in included studies}

Study quality was assessed for risk of bias using the Risk of Bias assessment tool from the Cochrane Handbook for Systematic Reviews of Interventions (Higgins \& Green, 2008). Six specific domains were addressed; (a) selection bias (random sequence generation and allocation concealment), (b) performance bias (blinding of participants and personnel), (c) attrition bias (incomplete outcome data) (d) detection bias (blinding of outcome assessment), (e) selective reporting bias (selective outcome reporting) and (f) any other potential sources of bias. Two authors (RN and MT) independently assessed the 'risk' of bias within each included study. Each domain was rated as low risk of bias, high risk of bias or unclear risk of bias.

Studies were considered high risk of bias when at least one of the criteria were judged as having a high risk of bias in any one of the criteria. Overall risk of bias was assessed as unclear if one or more of the criteria was assessed as unclear, but none were assessed as having a high risk of bias. Studies were considered low risk of bias if all criteria were assessed as low. Any disagreements were discussed until a consensus was reached.

\subsubsection{Data Synthesis}

169 Extracted study characteristics, intervention designs, intervention duration, theoretical 170 frameworks and outcome measures were summarised in tabular form and described. Studies were synthesized per outcome measure. Meta-analyses using a Random Effects (RE) model were then conducted using Review Manager 5.4. (Cochrane Collaboration, 2014). Each complex intervention differed in size of intervention type, setting and number of participants and therefore a random-effects meta-analysis was performed for each outcome due to the 
differences in variables (Clark \& Linzer, 2015; Borenstein et al. 2010; Brockwell \& Gordon, 2001; Hedges \& Vevea, 1998). A meta-analysis was undertaken if at least two similar comparisons could be performed (Ahn \& Kang, 2018; Bown \& Sutton, 2010) and suitable data were available.

Continuous outcomes were reported differently across studies. Some studies reported the mean score post-intervention for the outcomes at follow up, whilst others reported mean change from baseline, therefore these studies were split into two separate forest plots. Where possible, the mean difference from baseline to follow up was used in analyses. When the mean difference from baseline was not reported, we extracted the relevant data at the final time point. When studies used different outcome scales to measure an outcome of mental health, the results were calculated by standardised mean differences (SMDs). As per the guidance in the Cochrane Handbook of Systematic Reviews (2019), the final values and change scores were not combined as SMD. Therefore, separate meta-analyses were conducted. Where data were presented separately by gender or multiple intervention groups, we combined these in RevMan. Two studies (Goldfield et al. 2015; Daley et al. 2006) consisted of more than one exercise intervention group and therefore the data from both groups were combined during the analysis process. Funnel plots were used to examine any publication or reporting bias in the included studies (Hoffman, 2015).

Heterogeneity was assessed among the studies by examining forest plots and the $I^{2}$ statistic. This allows for a measure of the extent of the variation between the intervention effects among the different included studies (Borenstein et al. 2010; Higgins \& Green, 2008). Zero percent indicates no heterogeneity present, while 25 percent, 50 percent and 75 percent indicate low, moderate and high effects sizes of heterogeneity respectively (Werner-Seidler et al. 2017; Higgins et al. 2003). The meta-analyses were conducted to compare the intervention and control groups on the primary outcomes at post-intervention. The variability in participants, 
intervention components and outcomes of the included studies presented within this review indicate clinical heterogeneity may exist in the dataset. This can cause significant statistical heterogeneity therefore sub-group analyses were conducted to highlighted relevant clinical information (Gagnier et al. 2012). Subgroup analysis were conducted to examine any significant differences between solely physical activity-based interventions and multicomponent interventions included within the review. An overall effect size, the confidence interval and level of heterogeneity are presented in the following sections. Finally, studies that were not included in the meta-analysis were described narratively.

208

\section{Results}

210

\subsection{Search results}

211

Following the initial search of databases; 4,518 articles were identified using the search strategy (Fig 1). Articles were uploaded onto Covidence and duplicates were removed, leaving 2,795 articles. Titles and abstracts were screened and a further 2,682 articles removed, leaving 113 articles for full-text review. Studies were excluded during full-text screening for various reasons which are outlined in the characteristics of excluded studies table (S3 file). During this phase one article was merged as the papers were from the same study but included different time-points from baseline to twelve-month follow-up (Melnyk et al. 2015; Melnyk et al. 2013). Thirteen studies (from fourteen articles) published between 1982-2018, met the eligibility criteria for inclusion in the review. 


\subsection{Characteristics of included studies}

The studies were carried out in different countries with the majority were conducted in the USA $(n=7)$. One study was conducted in each of the following countries: England, Portugal, China, Korea, Columbia, Germany and Uganda. The included studies (Table 1) were conducted in different settings, ten interventions were based in the school setting, four were based in a hospital or clinical setting and two were set in the community setting. A majority of the studies $(\mathrm{n}=11)$ included both adolescent male and female participants (Andias et al. 2018; Frank et al. 2017; Carter et al. 2015; Goldfield et al. 2015; Melnyk et al. 2015; Velasquez et al. 2015; Richards et al, 2014; Khalsa et al. 2012; Melnyk et al. 2009; Daley et al. 2006; Lau et al. 2004) two studies included only female (Jeong et al. 2005) while only one of the studies included only male participants (Hilyer et al. 1982).

The included studies included interventions with a broader population which allows a level of generalisability across the results. Three studies were conducted in adolescents with obesity (Goldfield et al. 2015; Daley et al. 2006; Lau et al. 2004), three were carried out with adolescents from low income or poverty catchment areas (Frank et al. 2017; Velasquez et al. 2015; Richards et al. 2014), two were conducted with adolescents with high depression scores or receiving treatment for depression (Carter et al. 2015; Jeong et al. 2005). One study was conducted in the following adolescent populations, youth offenders (Hilyer et al. 1982); from a Hispanic background (Melnyk et al. 2009), culturally diverse background (Melnyk et al. 2015), rural community (Khalsa et al. 2012) and those adolescents suffering from chronic neck pain (Andias et al. 2018). Data was included for 1,928 participants with ages ranging from 10 to 19 years old. 
A variety of instruments were employed across the thirteen studies for anxiety, depression and stress outcome measures (S4). The use of difference outcome measures introduces methodological heterogeneity due to differences in study design, risk of bias and assessment measures. Of the included studies, eleven reported a measure of depression (Melnyk et al. 2013, Carter et al. 2015; Goldfield et al. 2015; Melnyk et al. 2015; Velasquez et al. 2015; Richards et al, 2014; Khalsa et al. 2012; Melnyk et al. 2009; Daley et al. 2006; Lau et al. 2004; Jeong et al. 2005; Lau et al. 2004; Hilyer et al. 1982), seven reported general anxiety (Carter et al. 2015; Richards et al. 2014; Melnyk et al. 2013; Khalsa et al. 2012; Melnyk et al. 2009; Jeong et al. 2005; Lau et al. 2004) and two reported state and trait anxiety (Andias et al. 2018; Hilyer et al. 1982). Furthermore, two studies examined different domains of stress (Frank et al. 2017; Khalsa et al. 2012), while test anxiety (Khalsa et al. 2012) were only reported in a single study.

\subsection{Interventions}

Within the included studies, several different types of physical activity were included in the interventions; including yoga $(n=3)$, strength, endurance and resistance type exercises $(n=2)$, aerobic exercises (walking, badminton, climbing, Frisbee, etc.) $(n=4)$, fitness training (e.g. circuits) $(\mathrm{n}=2)$, dance movement $(\mathrm{n}=1)$ and football $(\mathrm{n}=1)$. The interventions included four physical activity and educational sessions, two physical activity and counselling sessions and one study implementing a physical activity and behaviour modification intervention. Six studies offered physical activity only interventions. All 13 studies included interventions that ran for less than one year. Interventions lasted between four weeks and six months. Control groups within each study involved, seven studies with no change to their normal routine and no intervention (Andias et al. 2018; Frank et al. 2017; Velasquez et al. 2015; Richards et al. 
2014; Daley et al. 2006; Jeong et al. 2005), two involved treatment as usual control groups (Carter et al. 2015; Hilyer et al. 1982), two included business as usual with dietary advice (Goldfield et al. 2015; Lau et al. 2004) and two involved educational health advice (Melnyk et al. 2015; Melnyk et al. 2009). Four of the 13 studies explicitly labelled a theoretical framework in informing the intervention. Two theories were cited; cognitive behaviour theory $(n=2)$, and transtheorectical model $(\mathrm{n}=2)$.

\subsection{Risk of bias in included studies}

The risk of bias across all domains for the studies included in the review is presented in Figs 2 and 3. Frequently, a number of studies were reported as an 'unclear' risk of bias across several domains, this judgement was often obtained due to insufficient information. Overall risk of bias was high for eight of the included studies (Andias et al. 2018; Frank et al. 2017; Carter et al. 2015; Richards et al. 2014; Khalsa et al. 2012; Daley et al. 2006; Lau et al. 2004; Hilyer et al. 1982) and an unclear risk of bias was reported overall in three studies (Goldfield et al. 2015; Jeong et al. 2005; Velasquez et al. 2015). Two studies were reported as low risk of bias (Melnyk et al. 2015; Melnyk et al. 2009). This level of evidence may suggest that physical activity components within interventions may improve mental health outcomes however no significant effect is evident, therefore these results must be viewed with caution due to the risk of bias across all included studies.

\section{Please insert Figures 2 and 3 here.}

Over 50 percent of included studies $(n=7)$ were judged unclear to high risk of bias for incomplete outcome data (attrition bias). A number of these studies failed to highlight their intent-to-treat analysis process which resulted in unclear and high risk in a majority of the 
included studies, this introduces possible bias, high methodological heterogeneity and raises uncertainty about the results. Around 70 per cent of the studies were found to be free of selective reporting, however for the other 30 per cent it was impossible to know if all outcomes were all reported due to no published study protocol.

Another notable risk of bias and methodological weakness within the included studies was the lack of blinding (performance and detection bias) with around 40 per cent of studies demonstrating unclear to high risk of bias. Seven studies were judged as high risk while six were judged unclear risk for this domain. Overall the risk of bias from blinding can be reported as high with a number of studies not implementing full blinding procedures or provide insufficient information on blinding within their study or protocol. For example, the mental health outcomes in all studies were assessed through a self-reported questionnaire. There is also a chance that these participants may have been aware of the outcomes being assessed within the study. Evidence suggests that a lack of blinding can affect participant outcomes or introduce bias into the assessment of outcomes (Karanicolas, Farrokhyar \& Bhandari, 2010; Higgins \& Green, 2008). Furthermore, the unclear risk of bias for blinding could suggest bias is present in the intervention treatment which could impact the reliability of the results (Boutron et al. 2007).

\subsection{Effects of interventions}

Of the thirteen studies assessed, only eleven provided sufficient information to be included in the meta-analyses (Melnyk et al. 2015; Carter et al. 2015; Goldfield et al. 2015; Velasquez et al. 2015; Richards et al. 2014; Khalsa et al. 2012; Melnyk et al. 2009; Daley et al. 2006; Jeong et al. 2005; Lau et al. 2004; Hilyer et al. 1982). The additional two studies were included in the qualitative synthesis (Andias et al. 2018, Frank et al. 2017). 


\subsection{Synthesis of Results from Meta-Analysis}

Funnel plots (S5 file) displayed asymmetry suggesting that publication bias may be present in the included studies. This could be due to study effect sixes and level of heterogeneity (Lau et al. 2006; Tang and Liu, 2000). These findings also suggest that there is evidence of publication/reporting bias.

\subsubsection{Effect on Anxiety}

Seven studies including a total of 1,233 participants examined the impact of physical activity interventions on anxiety, five of these studies examined mean anxiety follow up (Fig 4a) and two examined change in anxiety from baseline (Fig $4 b$ ). The effect of physical activity on anxiety at follow was not statistically significant (SMD $0.04 ; 95 \% \mathrm{CI}-0.20,0.28 ; \mathrm{I}^{2}=55 \%$ ) or when measured as change from baseline (SMD -0.33; 95\% CI -0.68, 0.03; $\mathrm{I}^{2}=0$ ). A subgroup analysis revealed no statistically significant difference for solely physical activity-based interventions or multi-component interventions.

\subsubsection{Effect on Depression}

Twelve studies, including a total of 1,726 participants, examined the effect of a physical activity intervention on depression. Six of these studies examined depression as a mean at follow up (Fig 5a) while five of the included studies examined depression as a change from baseline (Fig 5b). Depression as a mean at intervention follow up was not statistically significant (SMD 0.09; 95\% CI $-0.20,0.40 ; \mathrm{I}^{2}=72 \%$ ). A subgroup analysis comparing physical activity $(\mathrm{p}=0.37)$ alone against multi-component $(\mathrm{p}=0.25)$ studies also indicated no significant difference existed for either intervention type. Depression as a change from 
baseline was also was also not statistically significant (SMD -0.11; $95 \%$ CI $-0.29,0.07 ; \mathrm{I}^{2}=$ $0 \%)$. A subgroup analysis revealed no statistically significant difference for solely physical activity-based interventions or multi-component interventions.

\section{Please insert Figure 5 here.}

\subsection{Synthesis of Findings Not Included in Meta-Analysis}

\subsubsection{Effect on anxiety}

The study by Andias et al. (2018) could not be included within the meta-analysis as it reported the mean difference in state anxiety and trait anxiety and therefore could not be compared to the other study which examined state and trait anxiety through mean at follow up. This study found that anxiety exhibited no significant difference $(\mathrm{p}=0.09)$ between the control and intervention groups at the end of the 4-week intervention. In addition, there was no significant difference for trait anxiety $(\mathrm{p}=0.11)$ between the control and intervention groups at the end of the 4-week intervention. Post intervention, the experimental group had lower trait and state anxiety scores than the control group. A study, by Hilyer et al. (1982) measured state anxiety and trait anxiety, examining the effects of a physical fitness training and counselling treatment programme for youth offenders. This study examined mean score at follow up and therefore could not be compared to Andias et al. (2018) in a meta-analysis. The authors reported a significant difference between the intervention and control groups in trait anxiety $(\mathrm{p}<0.001)$. State anxiety showed no statistically significant difference between the intervention and control groups ( $\mathrm{p}=0.06$ ); however, state anxiety decreased in the intervention group and increased in the control group. 
Only one study examined the concept of test anxiety: Khalsa et al. (2012) reported that while there was no statistically significant difference $(p=0.15)$ between the Yoga and control groups, the Yoga group exhibited lower test anxiety scores compared to the control group postintervention.

\subsubsection{Effects on stress}

Two studies reported on different domains of stress (Frank et al. 2017; Khalsa et al. 2012). Frank et al. (2017) examined seven aspects of stress response; problem solving, emotional regulation, emotional expression, secondary engagement, positive thinking, cognitive restructuring and acceptance. Statistically significant differences were found between the intervention and control groups in emotional regulation $(\mathrm{p}=0.05)$, positive thinking $(\mathrm{p}=0.01)$, secondary engagement $(p=0.01)$ and cognitive restructuring $(p=0.01)$. No significant differences were found in problem solving $(p=0.86)$ or emotional expression $(p=0.12)$ or acceptance $(\mathrm{p}=0.57)$. Furthermore, Khalsa et al. (2012) reported that while the intervention group had lower scores on the social stress domain than the control group the difference was not statistically significant $(\mathrm{p}=0.15)$.

\section{Discussion}

\subsection{Summary of main results}

The primary aim of this review was to examine the effects of physical activity interventions on the mental health outcomes of young people. The review identified eleven RCT's and two cluster-RCT's, with more than 1,500 participants, examining the effects of different interventions incorporating elements of physical activity to improve anxiety, depression and stress outcomes in adolescents. The meta-analyses updated the constantly expanding literature on the effects of physical activity intervention on mental health outcome in adolescents. The 
results indicated slight improvements in anxiety, depression and stress scores; however, the results were not statistically significant. Previous research also highlights that while there is only a small effect, there is an evident association between physical activity and mental health outcomes (Biddle et al. 2019; Camero et al. 2012; Biddle et al. 2011; Calfas \& Taylor, 1994). The findings of the current review are also consistent with the results of the systematic review by Camero et al. (2012) which indicated that there were no statistically significant differences in the determinants of psychological health, i.e. anxiety and depression. However, a longitudinal study by Jewett et al. (2014) examined mental health and involvement in school sport, suggesting that increased involvement in physical activity was a statistically significant predicator of lower stress and depression levels. Similarly, a review by Carter et al. (2016) demonstrated that exercise could have a statistically significant moderate effect on reducing depressive symptoms which was not evidenced in this study. The findings of the review in this study included a broader representation of the adolescent population and demonstrated higher levels of heterogeneity within the findings, which could have influenced the overall results and difference within the inclusion/exclusion criteria compared to the review by Carter et al. (2016).

The results of the meta-analyses of included studies were variable as indicated by the mostly moderate effect of heterogeneity. This might be explained by the difference in intervention duration and post-test data collection time points. The findings also indicated that research amongst the adolescent population often focuses on the physical activity interventions with depression as the outcome with few studies the effects of physical activity interventions on anxiety. The thirteen included studies involved multi-component interventions which utilised physical activity as a main component or solely physical activity interventions. It is difficult to isolate whether it was the physical-activity component of the multi-component 
interventions that caused the change because they included other factors/components particularly as there was no difference identified in the sub-group analysis.

Moreover, the adolescent population who are involved in the intervention programmes were often included for reasons other than mental health issues; for example, obesity (Goldfield et al. 2015) or pain management (Andias et al. 2018) which may influence the mental health outcomes examined within this review. There are evident links between the psychological and physiological mechanisms and improvements in mental health and well-being (Warburton et al. 2006; Andersen \& Sutherland, 2001). It is evident from the findings of the meta-analyses that the relationship between mental health outcomes and physical activity interventions is still not fully clear. This relationship could also be influenced by other factors such as gender, age, socioeconomic background and intervention setting.

\subsection{Summary of Risk of Bias from Included Studies}

A majority of the included studies were assessed as unclear or high risk. The lack of published protocols and details within the study hampered the reviewers' ability to assess risks of bias across the domains. Attribution bias was also evident within a number of studies and was particularly problematic in the larger studies and those conducted outside the school setting.

\subsection{Limitations}

This systematic review and meta analyses has several limitations. Firstly, whilst the search strategy used was comprehensive and included grey literature, it excluded conference proceedings and abstracts. Secondly, the articles included within the study were in English, thereby possibly missing relevant articles in other languages. Given the growing evidence base for mental health and physical activity interventions in countries such as China and Portugal it is important for future researchers to conduct additional searches for non-English publications. 
448 Thirdly, the choice of databases could be a limitation and several studies may have been

449 missed. Furthermore, it is also possible that a level of bias was introduced during the review

450 process despite a protocol being implemented to reduce bias. Potential bias is possible by using

451 a random effects model as this approach does not estimate separate effect (Clark \& Linzer,

452 2015). A fourth limitation is the lack of consistency in how the outcomes were measured across the studies; often the mental health outcomes of stress, anxiety and depression were assessed using different instruments. Finally, several attributes of the included studies may have limited the review result:; (a) the variability of intervention duration, activities and settings; (b) the lack of theoretical underpinnings; and (c) the variety of instruments and data collection time points assessing mental health outcomes.

The strengths of the review include adherence to the review protocol (Gilbody, 2007) and the inclusion of a meta-analysis. Conducting a meta-analysis further increases the strength of the study in regard to interpreting results across studies to examine the intervention effects. The study selection screening process and quality assessment was performed by two researchers, with initial disagreement being resolved by consensus. Furthermore, a solid search strategy was adopted to maximize the likelihood of capturing all relevant studies. Another strength of the review was that all included studies were RCT's and provided details on the randomization procedures employed for sequence generation in each study. Studies included were also found to be free of selective reporting; however, because many of these studies did not have published protocols it is impossible to know for certain if all outcomes were reported on.

5. Conclusions

471 The present systematic review and meta-analysis has investigated the effects of physical activity interventions on mental health outcomes in adolescents. The ability of physical activity 
components within interventions to produce meaningful change in anxiety, depression and stress outcomes in adolescents remains unclear as the results of the meta-analyses showed no overall affect, suggesting that there is no clear benefit of using this component. Additionally, the number of studies contributing sufficient evidence is low which may hamper this evidence. Due to the high and unclear risk of bias in several studies, these results should be interpreted with caution, as it is uncertain whether using physical activity within intervention programmes can interventions improve anxiety, depression and stress outcomes in young people. Further work is required to determine the most suitable approach to creating an intervention with physical activity components to improve mental health outcomes. This should include type of physical activity, intensity of physical activity and multiple outcomes of mental health e.g. anxiety, stress, depression, self-esteem, body image.

\section{References}

Ahn, E., \& Kang, H. (2018) Introduction to systematic review and meta-analysis. Korean $J$ Anesthesiol. 71:103-12.

Andersen, M.B. \& Sutherland, G. (2001) Working Out Those Tensions: Exercise and the Reduction of Stress. In: Mostofsky, DL. \& Zaichoway LD. (eds.). Medical and Psychological Aspects of Sport and Exercise. Morganstown, Virginia: Fitness Information Technology; 1932.

Andias, R., Neto, M., \& Silva, A. G. (2018). The effects of pain neuroscience education and exercise on pain, muscle endurance, catastrophizing and anxiety in adolescents with chronic idiopathic neck pain: a school-based pilot, randomized and controlled study. Physiotherapy theory and practice, 34(9), 682-691. 
Archer, T., \& Garcia, D. (2014). Physical exercise influences academic performance and well-being in children and adolescents. International Journal of School and Cognitive Psychology, 1(1), e102.

Ardoy, D. N., Fernández-Rodríguez, J. M., Jiménez-Pavón, D., Castillo, R., Ruiz, J. R., \&

Ortega, F. B. (2014). A physical education trial improves adolescents' cognitive performance and academic achievement: the EDUFIT study. Scandinavian journal of medicine \& science in sports, 24(1), e52-e61.

Biddle, S.J.H., \& Asare, M. (2011) Physical activity and mental health in children and adolescents: a review of reviews. Br J Sports Med. 886-95.

Biddle, S.J., Ciaccioni, S., Thomas, G. and Vergeer, I., (2019). 'Physical activity and mental health in children and adolescents: An updated review of reviews and an analysis of causality'. Psychology of Sport and Exercise, 42, .146-155.

Bonhauser, M., Fernandez, G., Püschel, K., Yañez, F., Montero, J., Thompson, B., \& Coronado, G. (2005). Improving physical fitness and emotional well-being in adolescents of low socioeconomic status in Chile: results of a school-based controlled trial. Health Promotion International, 20(2), 113-122.

Borenstein, M., Hedges, L. V., Higgins, J. P., \& Rothstein, H. R. (2010). A basic introduction to fixed-effect and random-effects models for meta-analysis. Research synthesis methods, 1(2), 97-111.

515 Boutron, I., Guittet, L., Estellat, C., Moher, D., Hróbjartsson, A., \& Ravaud, P. (2007). 516 Reporting methods of blinding in randomized trials assessing nonpharmacological 517 treatments. PLoS medicine, 4(2).

518 Bown, M. J., \& Sutton, A. J. (2010). Quality control in systematic reviews and metaanalyses. European Journal of Vascular and Endovascular Surgery, 40(5), 669-677. 
Brockwell, S. E., \& Gordon, I. R. (2001). A comparison of statistical methods for metaanalysis. Statistics in medicine, 20(6), 825-840.

Burnett-Zeigler, I., Walton, M. A., Ilgen, M., Barry, K. L., Chermack, S. T., Zucker, R. A., ... \& Blow, F. C. (2012). Prevalence and correlates of mental health problems and treatment among adolescents seen in primary care. Journal of Adolescent Health, 50(6), 559-564. Calfas, K. J., \& Taylor, W. C. (1994). Effects of physical activity on psychological variables in adolescents. Pediatric exercise science, 6(4), 406-423.

Camero, M., Hobbs, C., Stringer, M., Branscum, P., \& Taylor, E. L. (2012). A review of physical activity interventions on determinants of mental health in children and adolescents. International Journal of Mental Health Promotion, 14(4), 196-206.

Carter, T., Guo, B., Turner, D., Morres, I., Khalil, E., Brighton, E., ... \& Callaghan, P. (2015). Preferred intensity exercise for adolescents receiving treatment for depression: a pragmatic randomised controlled trial. BMC psychiatry, 15(1), 247.

Carter, T., Morres, I. D., Meade, O., \& Callaghan, P. (2016). The Effect of Exercise on Depressive Symptoms in Adolescents: A Systematic Review and Meta-Analysis. Journal of the American Academy of Child and Adolescent Psychiatry, 55(7), 580-590.

Clark, T. S., \& Linzer, D. A. (2015). Should I use fixed or random effects?. Political Science Research and Methods, 3(2), 399-408.

Cochrane Collaboration (2019) 9.4.5.2 Meta-analysis of change scores. Retrieved from: https://handbook-5-1.cochrane.org/chapter_9/9 4_5_2_meta_analysis_of_change_scores.htm Covidence Systematic Review Software (2015). Melbourne, Australia: Veritas Health Innovation, 2015. Retrieved from: www.covidence.org

Daley, A. J., Copeland, R. J., Wright, N. P., Roalfe, A., \& Wales, J. K. (2006). Exercise therapy as a treatment for psychopathologic conditions in obese and morbidly obese adolescents: a randomized, controlled trial. Pediatrics, 118(5), 2126-2134. 

activity programs for promoting physical activity and fitness in children and adolescents aged 6 to 18. Cochrane database of systematic reviews, (2): 1-259.

Doran, C.M. \& Kinchin, I., (2019). A review of the economic impact of mental illness. Australian Health Review, 43(1), pp.43-48. systematic review of the psychological and social benefits of participation in sport for children and adolescents: informing development of a conceptual model of health through sport. International journal of behavioral nutrition and physical activity, 10(1), 98.

Evans T. (2019) Driving Demand and Delivery for Mental Health. American Journal of Public Health, 109(S3): S164-S164.

Evans, R.E., Craig, P., Hoddinott, P., Littlecott, H., Moore, L., Murphy, S., O'Cathain, A., interventions need to be adapted and/or re-evaluated in new contexts? The need for guidance. J Epidermiol Community Health, 73(6) pp.481-482.

Fazel, M., Hoagwood, K., Stephan, S. \& Ford, T., (2014). Mental health interventions in schools in high-income countries. The Lancet Psychiatry, 1(5), 377-387. nutrition, 2(3a), 411-418.

Frank, J. L., Kohler, K., Peal, A., \& Bose, B. (2017). Effectiveness of a school-based yoga program on adolescent mental health and school performance: Findings from a randomized controlled trial. Mindfulness, 8(3), 544-553.

567 Gagnier, J. J., Moher, D., Boon, H., Beyene, J., \& Bombardier, C. (2012). Investigating clinical heterogeneity in systematic reviews: a methodologic review of guidance in the literature. $B M C$ medical research methodology, 12(1), 111. 
570 Gilbody, S. (2007) Systematic reviews and meta-analysis. In: Slade, M. \& Priebe, S. (eds.).

571 Choosing Methods in Mental Health Research: Mental Health Research from Theory to

572 Practice. East Sussex: Taylor and Francis. 99-112.

573 Goldfield, G. S., Kenny, G. P., Alberga, A. S., Prud'homme, D., Hadjiyannakis, S., Gougeon, 574 R., ... \& Wells, G. A. (2015). Effects of aerobic training, resistance training, or both on 575 psychological health in adolescents with obesity: The HEARTY randomized controlled trial. Journal of consulting and clinical psychology, 83(6), 1123.

\section{7}

Gråstén, A., (2017). 'School-based physical activity interventions for children and youth: Keys for success'. Journal of Sport and Health Science. 6(3), 290-291.

He, J. P., Paksarian, D., \& Merikangas, K. R. (2018). Physical activity and mental disorder among adolescents in the United States. Journal of Adolescent Health, 63(5), 628-635.

Hedges, L. V., \& Vevea, J. L. (1998). Fixed-and random-effects models in metaanalysis. Psychological methods, 3(4), 486.

Higgins, J. P., Thompson, S. G., Deeks, J. J., \& Altman, D. G. (2003). Measuring inconsistency in meta-analyses. Bmj, 327(7414), 557-560.

Higgins, J.P. \& Green, S. Cochrane Handbook for Systematic Reviews of Interventions. Chichester: John Wiley \& Sons Ltd.

Hilyer, J. C., Wilson, D. G., Dillon, C., Caro, L., Jenkins, C., Spencer, W. A., ... \& Booker, W. (1982). Physical fitness training and counselling as treatment for youthful offenders. Journal of Counselling Psychology, 29(3), 292.

590 Hoffman, J.I., (2015). Biostatistics for medical and biomedical practitioners. London: Academic press. movement therapy improves emotional responses and modulates neurohormones in adolescents with mild depression. International journal of neuroscience, 115(12), 1711-1720. 
Jewett, R., Sabiston, C. M., Brunet, J., O'Loughlin, E. K., Scarapicchia, T., \& O'Loughlin, J. (2014). School sport participation during adolescence and mental health in early adulthood. Journal of adolescent health, 55(5), 640-644.

Karanicolas, P. J., Farrokhyar, F., \& Bhandari, M. (2010). Blinding: Who, what, when, why, how?. Canadian Journal of Surgery, 53(5), 345-348.

600 Keyes C. (2013). Mental Well-Being - International Contributions to the Study of Positive 601 Mental Health. New York: Springer.

602

Khalsa, S. B. S., Hickey-Schultz, L., Cohen, D., Steiner, N., \& Cope, S. (2012). Evaluation of 603 the mental health benefits of yoga in a secondary school: A preliminary randomized controlled 604 trial. The journal of behavioral health services \& research, 39(1), 80-90.

605

Khan L. (2016) Missed Opportunities. A review of recent evidence into children and young 606 people's mental health. Centre for Mental Health; London

607

Kuhn, C., Aebi, M., Jakobsen, H., Banaschewski, T., Poustka, L., Grimmer, Y., ... \& 608 Steinhausen, H. C. (2017). Effective mental health screening in adolescents: should we collect 609 data from youth, parents or both?. Child Psychiatry \& Human Development, 48(3), 385-392. Lai, H. R., Lu, C. M., Jwo, J. C., Lee, P. H., Chou, W. L., \& Wen, W. Y. (2009). The effects of a self-esteem program incorporated into health and physical education classes. Journal of Nursing Research, 17(4), 233-240. Lam, L.C.W. (2016) 'Recent developments of physical activity interventions as an adjuvant therapy in mental disorders', in: Lam, L.C.W. and Riba, M. (eds.). Physical Exercise Interventions for Mental Health. New York: Cambridge University Press. 1-8.

616 Lau, J., Ioannidis, J. P., Terrin, N., Schmid, C. H., \& Olkin, I. (2006). The case of the 617 misleading funnel plot. Bmj, 333(7568), 597-600. 
Lau, P. W., Yu, C. W., Lee, A., \& Sung, R. Y. (2004). The physiological and psychological

619

620

621

622

623

624

625

626

627

628

629

630

631

632

633

634

635

636

637

638

639

640

641

642

effects of resistance training on Chinese obese adolescents. Journal of Exercise Science and Fitness, 2(2), 115-120.

Lubans, D. R., Plotnikoff, R. C., \& Lubans, N. J. (2012). A systematic review of the impact of physical activity programmes on social and emotional well-being in at-risk youth. Child and adolescent mental health, 17(1), 2-13.

Lubans, D., Richards, J., Hillman, C., Faulkner, G., Beauchamp, M., Nilsson, M., ... \&

Biddle, S. (2016). Physical activity for cognitive and mental health in youth: a systematic review of mechanisms. Pediatrics, 138(3), e20161642.

McGorry, P., Bates, T. \& Birchwood, M., (2013). Designing youth mental health services for the 21st century: examples from Australia, Ireland and the UK. The British Journal of Psychiatry, 202(s54), s30-s35.

Melnyk, B. M., Jacobson, D., Kelly, S. A., Belyea, M. J., Shaibi, G. Q., Small, L., ... \& Marsiglia, F. F. (2015). Twelve-Month Effects of the COPE Healthy Lifestyles TEEN Program on overweight and depressive symptoms in high school adolescents. Journal of school health, 85(12), 861-870.

Melnyk, B. M., Jacobson, D., Kelly, S., Belyea, M., Shaibi, G., Small, L., ... \& Marsiglia, F. F. (2013). Promoting healthy lifestyles in high school adolescents: a randomized controlled trial. American Journal of Preventive Medicine, 45(4), 407-415.

Melnyk, B. M., Jacobson, D., Kelly, S., O'Haver, J., Small, L., \& Mays, M. Z. (2009). Improving the mental health, healthy lifestyle choices, and physical health of Hispanic adolescents: A randomized controlled pilot study. Journal of School Health, 79(12), 575-584. Mental Health Foundation (2013). Let's Get Physical: The Impact of Physical Activity on Wellbeing. London, 1-47. Retrieved from:

https://www.mentalhealth.org.uk/sites/default/files/lets-get-physical-report.pdf [Accessed: 

2016. Retrieved from:

https://www.mentalhealth.org.uk/sites/default/files/FF16\%20Northern\%20ireland.pdf Mental Health Foundation. (2018). Stigma and discrimination. Retrieved from:

Moses, T., (2010). Being treated differently: Stigma experiences with family, peers, and school staff among adolescents with mental health disorders. Social science \& medicine, 70(7), 985-993.

NAMI (2015). Mental Health by the Numbers | NAMI: National Alliance on Mental Illness.

Retrieved from: https://www.nami.org/Learn-More/Mental-Health-By-the-Numbers

National Collaborating Centre for Mental Health (Great Britain), National Institute for Health, Clinical Excellence (Great Britain), British Psychological Society, \& Royal College of Psychiatrists. (2011). Common mental health disorders: identification and pathways to care (Vol. 123). RCPsych Publications.

Olsson, C.A., Bond, L., Burns, J.M., Vella-Brodrick, D.A., and Sawyer, S.M. (2003) 'Adolescent resilience: a concept analysis'. Journal of Adolescence. 26(1), 1-11. Pincheiro, M., Ivandic, I., and Razzouk, D. (2017) 'The Economic Impact of Mental Health Health Economics. Switzerland: Springer, pp. 415-430. maintenance from adolescence to young adulthood associated with reduced CVD risk factors, improved mental health and satisfaction with life: the HUNT Study, Norway. International Journal of Behavioral Nutrition and Physical Activity, 9(1), 144. 
668 Review Manager-RevMan (2014). Version 5.3. Copenhagen: The Nordic Cochrane Centre, 669 The Cochrane Collaboration

670 Richards, J., Foster, C., Townsend, N., \& Bauman, A. (2014). Physical fitness and mental 671 health impact of a sport-for-development intervention in a post-conflict setting randomised 672 controlled trial nested within an observational study of adolescents in Gulu, Uganda. BMC 673 public health, 14(1), 619.

674 Royal College of Psychiatrists (2016) Values-Based Child and Adolescent Mental Health System Commission What Really Matters in Children and Young People’s Mental Health.

Retrieved from: https://www.rcpsych.ac.uk/pdf/Values-based\%20full\%20report.pdf

677 [Accessed 24 Oct. 2017].

678

Salmon, P. (2001). Effects of physical exercise on anxiety, depression, and sensitivity to stress: a unifying theory. Clinical psychology review, 21(1), 33-61.

680

Schofield, D., Cunich, M., Shrestha, R., Tanton, R., Veerman, L., Kelly, S. \& Passey, M., 681 (2019). Indirect costs of depression and other mental and behavioural disorders for Australia from 2015 to 2030. BJPsych Open, 5(3).

683

Sickel, A.E., Seacat, J.D. \& Nabors, N.A., (2019). Mental health stigma: Impact on mental 684 685 health treatment attitudes and physical health. Journal of health psychology, 24(5), pp.586599.

686 Disorders in Children and Youth? Journal of Child and Adolescent Behaviour, 4(4). Ströhle, A. (2009). Physical activity, exercise, depression and anxiety disorders. Journal of neural transmission, 116(6), 777-84.

Stubbs, B., Vancampfort, D., Hallgren, M., Firth, J., Veronese, N., Solmi, M., Brand, S., 692 Cordes, J., Malchow, B., Gerber, M. \& Schmitt, A., (2018). EPA guidance on physical 
693

694

695

696

697

698

699

700

701

702

703

704

705

706

707

708

709

710

711

712

713

714

715

activity as a treatment for severe mental illness: a meta-review of the evidence and Position Statement from the European Psychiatric Association (EPA), supported by the International Organization of Physical Therapists in Mental Health (IOPTMH). European Psychiatry, 54, $124-144$

Tang, J. L., \& Liu, J. L. (2000). Misleading funnel plot for detection of bias in metaanalysis. Journal of clinical epidemiology, 53(5), 477-484.

Trautmann, S., Rehm, J. \& Wittchen, H.-U. (2016) The economic costs of mental disorders. EMBO reports. e201642951.

Velásquez, A. M., López, M. A., Quiñonez, N., \& Paba, D. P. (2015). Yoga for the prevention of depression, anxiety, and aggression and the promotion of socio-emotional competencies in school-aged children. Educational Research and Evaluation, 21(5-6), 407-421.

Vigo, D.V., Kestel, D., Pendakur, K., Thornicroft, G.\& Atun, R., (2019). Disease burden and government spending on mental, neurological, and substance use disorders, and self-harm: cross-sectional, ecological study of health system response in the Americas. The Lancet Public Health, 4(2), pp.e89-e96.

Vina, J., Sanchis-Gomar, F., Martinez-Bello, V., \& Gomez-Cabrera, M. C. (2012). Exercise acts as a drug; the pharmacological benefits of exercise. British journal of pharmacology, 167(1), 1-12.

Warburton, D. E., Nicol, C. W., \& Bredin, S. S. (2006). Health benefits of physical activity: the evidence. Cmaj, 174(6), 801-809.

Weeks, C., Hill, V., \& Owen, C. (2017). Changing thoughts, changing practice: examining the delivery of a group CBT-based intervention in a school setting. Educational Psychology in Practice, 33(1), 1-15. 
Werner-Seidler, A., Perry, Y., Calear, A. L., Newby, J. M., \& Christensen, H. (2017). School-

717

718

719

720

721

722

723

724

725

726

727

728

729

730

731

732

733

734

735

736

737

738

739

740 based depression and anxiety prevention programs for young people: A systematic review and meta-analysis. Clinical psychology review, 51, 30-47.

Whiteford, H.A., Ferrari, A.J., Degenhardt, L., Feigin, V. \& Vos, T., (2013). The global burden of mental, neurological and substance use disorders: an analysis from the Global Burden of Disease Study 2010. PloS one, 10(2), p. e0116820.

who.int. (2019, November $\left.22^{\text {nd }}\right)$ New WHO-led study says majority of adolescents worldwide are not sufficiently physically active. Retrieved from: https://www.who.int/newsroom/detail/22-11-2019-new-who-led-study-says-majority-of-adolescents-worldwide-arenot-sufficiently-physically-active-putting-their-current-and-future-health-at-risk

World Health Organization (2018, March 30th) Mental Health: Strengthening our Response, Retrieved from: https://www.who.int/en/news-room/fact-sheets/detail/mental-healthstrengthening-our-response

World Health Organization (2019, October $\left.2^{\text {nd }}\right) 10$ facts on mental health Retrieved from: https://www.who.int/news-room/facts-in-pictures/detail/mental-health

\section{Abbreviations}

RE - Random Effects

SD - Standard Deviation

SMD - Standard Mean Difference

\section{Supporting Information}

S1 File: PRISMA checklist

S2 File: Search string - MEDLINE

S3 File: Excluded studies 
$741 \quad$ S4 File: Included studies outcomes and scales

742 S5 File: Funnel plots

743

744 Table Legend

745 Table 1: Characteristics of Included Studies

746

$747 \quad$ Figure Legend

748 Figure 1: PRISMA flow diagram

$749 \quad$ Figure 2: Risk of Bias graph

$750 \quad$ Figure 3: Risk of Bias summary

751 Figure 4a: Forest plot for anxiety at follow-up

752 Figure 4b: Forest plot for change in anxiety from baseline

753 Figure 5a: Forest plot for depression at follow-up

754 Figure 5b: Forest plot for change in depression from baseline 
Table 1. Characteristics of included studies

\begin{tabular}{|c|c|c|c|c|c|c|c|c|c|c|}
\hline $\begin{array}{l}\text { (Ref, } \\
\text { Year) } \\
\text { Country }\end{array}$ & $\begin{array}{l}\text { Type } \\
\text { of } \\
\text { Study }\end{array}$ & Setting & Population & $\mathbf{N}$ & $\begin{array}{l}\text { Intervention } \\
\text { Duration }\end{array}$ & $\begin{array}{l}\text { Intervention } \\
\text { Facilitator }\end{array}$ & $\begin{array}{l}\text { Intervention } \\
\text { Type } \\
\text { (I: Intervention, } \\
\text { C: Control) }\end{array}$ & $\begin{array}{l}\text { Intervention } \\
\text { Frequency }\end{array}$ & $\begin{array}{l}\text { Physical } \\
\text { activity } \\
\text { frequency } \\
\text { and } \\
\text { intensity } \\
\end{array}$ & $\begin{array}{l}\text { Theoretical } \\
\text { Framework }\end{array}$ \\
\hline $\begin{array}{l}\text { (Andias et } \\
\text { al. 2018) } \\
\text { Portugal }\end{array}$ & RCT & School & $\begin{array}{l}15-18 \text { years old } \\
\text { with chronic } \\
\text { idiopathic neck } \\
\text { pain }\end{array}$ & 43 & 4 weeks & Physiotherapists & $\begin{array}{l}\text { I: Neuroscience } \\
\text { education and } \\
\text { exercises } \\
\text { C: No } \\
\text { intervention and } \\
\text { no change to } \\
\text { their normal } \\
\text { routine. }\end{array}$ & $\begin{array}{l}\text { Once weekly } \\
\text { for } 45 \\
\text { minutes }\end{array}$ & $\begin{array}{l}15 \text { minutes } \\
\text { to } 45 \\
\text { minutes }\end{array}$ & Not stated \\
\hline $\begin{array}{l}\text { (Carter et } \\
\text { al. 2015) } \\
\text { United } \\
\text { States }\end{array}$ & RCT & Clinical & $\begin{array}{l}\text { 14-17 years old } \\
\text { receiving } \\
\text { treatment for } \\
\text { depression }\end{array}$ & 79 & 6 weeks & $\begin{array}{l}\text { Certified fitness } \\
\text { instructor and } \\
\text { project staff }\end{array}$ & $\begin{array}{l}\text { I: Circuit } \\
\text { Training } \\
\text { C: Treatment as } \\
\text { usual (included } \\
\text { psychological } \\
\text { therapies, } \\
\text { medication etc.) }\end{array}$ & $\begin{array}{l}\text { Twice weekly } \\
\text { for } 1 \text { hour }\end{array}$ & $\begin{array}{l}45 \text { minutes } \\
\text { of circuit } \\
\text { exercises, } \\
15 \text { minutes } \\
\text { of } \\
\text { stretching. }\end{array}$ & $\begin{array}{l}\text { Transtheoretical } \\
\text { Model }\end{array}$ \\
\hline $\begin{array}{l}\text { (Daley et } \\
\text { al. 2006) } \\
\text { England }\end{array}$ & RCT & School & $\begin{array}{l}\text { 11-16 years old } \\
\text { who have } \\
\text { obesity or } \\
\text { morbidly } \\
\text { obesity }\end{array}$ & 75 & 8 weeks & $\begin{array}{l}\text { One of study } \\
\text { authors }\end{array}$ & $\begin{array}{l}\text { I: Exercise } \\
\text { therapy and } \\
\text { exercise } \\
\text { counselling } \\
\text { (aerobic } \\
\text { exercises - e.g. } \\
\text { stepping, dance } \\
\text { mat, walking, } \\
\text { cycling, rowing) } \\
\text { or Exercise } \\
\text { Placebo } \\
\text { (stretching } \\
\text { exercises) } \\
\text { C: Usual Care } \\
\text { (waitlisted } \\
\text { control): }\end{array}$ & $\begin{array}{l}\text { Three times } \\
\text { weekly for } 1 \\
\text { hour }\end{array}$ & $\begin{array}{l}30 \text { minutes } \\
\text { of moderate } \\
\text { intensity } \\
\text { exercise } \\
(40-59 \% \\
\text { HR) }\end{array}$ & $\begin{array}{l}\text { Transtheorectical } \\
\text { Model }\end{array}$ \\
\hline
\end{tabular}




\begin{tabular}{|c|c|c|c|c|c|c|c|c|c|c|}
\hline $\begin{array}{l}\text { (Frank et } \\
\text { al. 2017) } \\
\text { United } \\
\text { States }\end{array}$ & RCT & School & $\begin{array}{l}\text { 11-15 years old } \\
\text { from a high } \\
\text { poverty } \\
\text { catchment }\end{array}$ & 159 & 16 weeks & Yoga instructor & $\begin{array}{l}\text { I: Classroom } \\
\text { based activities - } \\
\text { yoga and a } \\
\text { social-emotional } \\
\text { wellness } \\
\text { promotion } \\
\text { programme, } \\
\text { called } \\
\text { Transformative } \\
\text { Life Skills. } \\
\text { C: No } \\
\text { intervention - } \\
\text { continued with } \\
\text { business as usual } \\
\text { and attended } \\
\text { normal school } \\
\text { activity. }\end{array}$ & $\begin{array}{l}\text { Three-four } \\
\text { times weekly } \\
\text { for } 30 \\
\text { minutes. }\end{array}$ & $\begin{array}{l}15-20 \\
\text { minutes - } \\
\text { low } \\
\text { intensity }\end{array}$ & Not stated \\
\hline $\begin{array}{l}\text { (Goldfield } \\
\text { et al. 2015) } \\
\text { United } \\
\text { States }\end{array}$ & RCT & Community & $\begin{array}{l}14-18 \text { years old } \\
\text { with obesity }\end{array}$ & 298 & 22 weeks & Personal trainers & $\begin{array}{l}\text { I: Aerobic } \\
\text { Training group - } \\
\text { exercise and } \\
\text { dietary advice, } \\
\text { Resistance Group } \\
\text { - weight training } \\
\text { and dietary } \\
\text { advice. } \\
\text { Combined group } \\
\text { - aerobic and } \\
\text { resistance } \\
\text { training and } \\
\text { dietary advice. } \\
\text { C: No exercise } \\
\text { intervention, just } \\
\text { dietary advice. }\end{array}$ & $\begin{array}{l}\text { Four times } \\
\text { weekly for } 45 \\
\text { minutes }-90 \\
\text { minutes }\end{array}$ & $\begin{array}{l}45 \text { minutes } \\
\text { for both the } \\
\text { aerobic and } \\
\text { resistance } \\
\text { groups - } \\
65-85 \% \mathrm{HR} \\
\text { intensity; } \\
90 \text { minutes } \\
\text { for the } \\
\text { combined } \\
\text { group }\end{array}$ & Not stated \\
\hline
\end{tabular}




\begin{tabular}{|c|c|c|c|c|c|c|c|c|c|c|}
\hline $\begin{array}{l}\text { (Hilyer et } \\
\text { al. 1982) } \\
\text { United } \\
\text { States }\end{array}$ & RCT & School & $\begin{array}{l}15-18 \text { years old } \\
\text { youth offenders }\end{array}$ & 43 & 20 weeks & $\begin{array}{l}\text { Fitness } \\
\text { instructor/doctoral } \\
\text { student }\end{array}$ & $\begin{array}{l}\text { I: Fitness } \\
\text { Training and } \\
\text { normal } \\
\text { rehabilitation } \\
\text { C: Treatment as } \\
\text { usual - normal } \\
\text { rehabilitation }\end{array}$ & $\begin{array}{l}\text { Three } \\
\text { alternative } \\
\text { days each } \\
\text { week for } 1 \\
\text { hour and } 30 \\
\text { minutes }\end{array}$ & $\begin{array}{l}1 \mathrm{hr} \text { and } 15 \\
\text { minutes of } \\
\text { exercise }\end{array}$ & Not stated \\
\hline $\begin{array}{l}\text { (Jeong et } \\
\text { al. 2005) } \\
\text { Korea }\end{array}$ & RCT & School & $\begin{array}{l}15-16 \text { years old } \\
\text { with high } \\
\text { depression } \\
\text { scores but no } \\
\text { clinical } \\
\text { diagnosis }\end{array}$ & 40 & 12 weeks & Did not state & $\begin{array}{l}\text { I: Dance } \\
\text { Movement } \\
\text { Therapy } \\
\text { C: No treatment - } \\
\text { (waitlisted } \\
\text { control) }\end{array}$ & $\begin{array}{l}\text { Three times } \\
\text { weekly for } 45 \\
\text { minutes. }\end{array}$ & 45 minutes & Not stated \\
\hline $\begin{array}{l}\text { (Khalsa et } \\
\text { al. 2012) } \\
\text { United } \\
\text { States }\end{array}$ & $\mathrm{RCT}$ & School & $\begin{array}{l}15-19 \text { years old } \\
\text { from a rural } \\
\text { area }\end{array}$ & 100 & 11 weeks & Yoga instructor & $\begin{array}{l}\text { I: Yoga } \\
\text { C: No treatment }\end{array}$ & $\begin{array}{l}\text { Two to Three } \\
\text { times a week } \\
\text { for } 30-40 \\
\text { minutes. }\end{array}$ & $\begin{array}{l}30-40 \\
\text { minutes }\end{array}$ & Not stated \\
\hline $\begin{array}{l}\text { (Lau et al. } \\
\text { 2004) } \\
\text { China }\end{array}$ & RCT & Hospital & $\begin{array}{l}10-17 \text { years old } \\
\text { with obesity }\end{array}$ & 37 & 6 weeks & Fitness instructors & $\begin{array}{l}\text { I: Resistance } \\
\text { Training } \\
\text { C: No exercise } \\
\text { just nutrition } \\
\text { sessions }\end{array}$ & $\begin{array}{l}\text { Three times } \\
\text { weekly for } 1 \\
\text { hour. }\end{array}$ & $\begin{array}{l}\text { Resistance } \\
\text { exercises } \\
\text { for } 1 \text { hour - } \\
70-85 \% \text { HR }\end{array}$ & Not stated \\
\hline $\begin{array}{l}\text { (Melnyk et } \\
\text { al. 2009) } \\
\text { United } \\
\text { States }\end{array}$ & $\begin{array}{l}\text { Cluster } \\
\text { RCT }\end{array}$ & School & $\begin{array}{l}14-16 \text { years old } \\
\text { Hispanic } \\
\text { adolescents }\end{array}$ & 17 & 9 weeks & $\begin{array}{l}\text { High school } \\
\text { teacher }\end{array}$ & $\begin{array}{l}\text { I: Physical } \\
\text { activity (e.g. } \\
\text { walking) and a } \\
\text { healthy lifestyle } \\
\text { programme } \\
\text { involving } \\
\text { educational } \\
\text { information, role } \\
\text { playing, nutrition } \\
\text { etc. } \\
\text { C: Health topics } \\
\text { but no physical } \\
\text { activity. }\end{array}$ & $\begin{array}{l}\text { Two to three } \\
\text { times a week } \\
\text { for } 50 \\
\text { minutes }\end{array}$ & $\begin{array}{l}20 \text { minutes } \\
\text { of physical } \\
\text { activity. }\end{array}$ & $\begin{array}{l}\text { Cognitive } \\
\text { Behaviour } \\
\text { Theory }\end{array}$ \\
\hline $\begin{array}{l}\text { (Melnyk et } \\
\text { al. 2013, } \\
\text { 2015) }\end{array}$ & $\begin{array}{l}\text { Cluster } \\
\text { RCT }\end{array}$ & School & $\begin{array}{l}\text { 14-16 years old } \\
\text { culturally } \\
\text { diverse high }\end{array}$ & 697 & 15 weeks & $\begin{array}{l}\text { High school } \\
\text { teacher }\end{array}$ & $\begin{array}{l}\text { I: Physical } \\
\text { activity (e.g. } \\
\text { walking) and a }\end{array}$ & $\begin{array}{l}\text { Once a week } \\
\text { for } 50 \\
\text { minutes }\end{array}$ & $\begin{array}{l}20 \text { minutes } \\
\text { of physical } \\
\text { activity. }\end{array}$ & $\begin{array}{l}\text { Cognitive } \\
\text { Behaviour } \\
\text { Theory }\end{array}$ \\
\hline
\end{tabular}




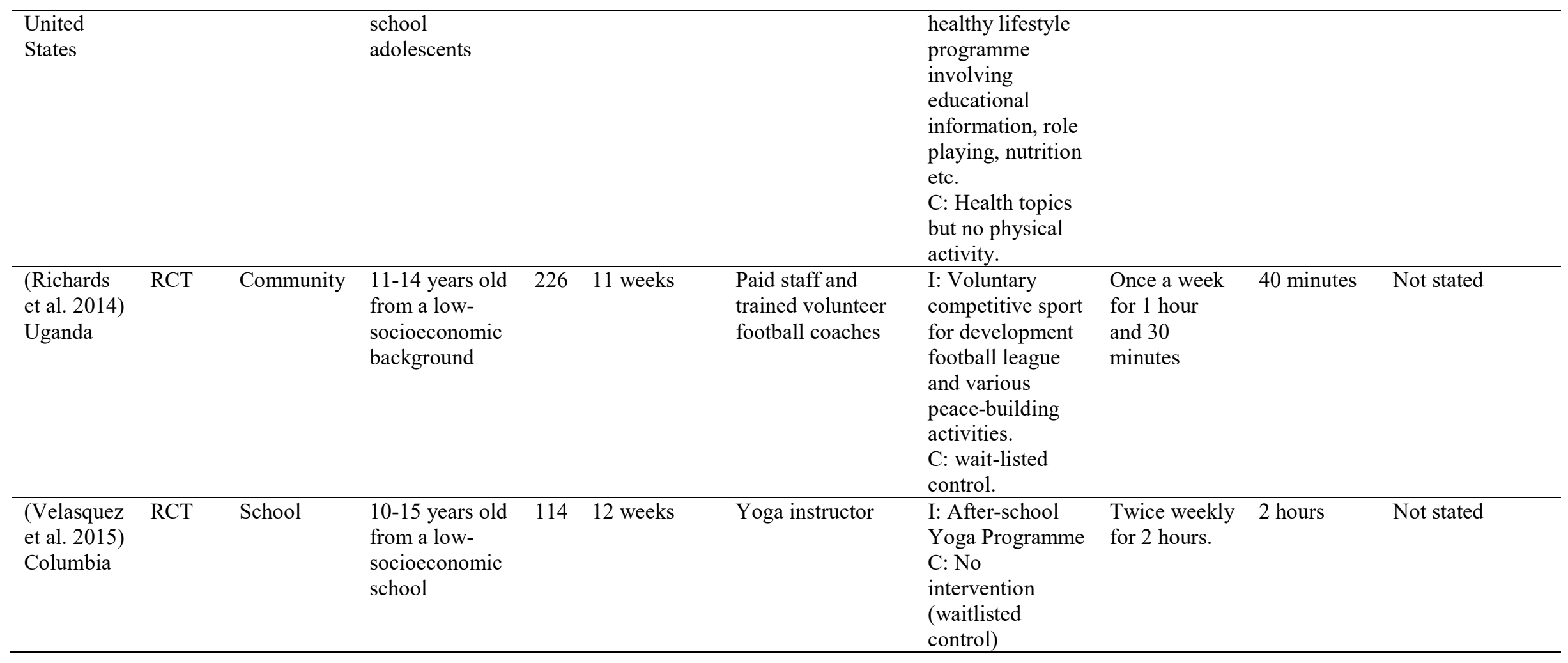

